\title{
Below the Tip of the Iceberg: Examining Early Childhood Participation in SNAP and TANF from Birth to Age Six
}

\author{
Colleen Heflin ${ }^{1}$ D $\cdot$ Michah W. Rothbart ${ }^{1} \cdot$ Mattie Mackenzie-Liu $^{1}$
}

Received: 15 January 2021 / Accepted: 19 May 2021 / Published online: 1 June 2021

(C) The Author(s), under exclusive licence to Springer Nature B.V. 2021

\begin{abstract}
In the United States, the SNAP and TANF programs provide financial support to low-income households with children. Yet, little is known about the extent of this support over the early childhood period or how program participation varies by race (or ethnicity) and metropolitan county residence. We use administrative data from Virginia to document participation in SNAP and TANF among children born between 2007 and 2010 during their early childhood period, which we define here as birth to age six. We find that participation in SNAP is about four times greater than participation in TANF and that most children begin their connection with the social welfare system in their birth year. Children who participate earlier in life tend to stay connected over a longer portion of the early childhood period, although SNAP participation peaks around ages 3-4 while TANF peaks earlier, around ages 2-3. Most households on SNAP do not receive TANF, but only about 1 in 12 children on TANF do not receive SNAP. Finally, over the early childhood period, on average, just under 1 in 2 children in Virginia participated in SNAP or TANF but demography plays an important role in this process: The level of cumulative receipt is 1 in 4 among White children, 1 in 2 among Hispanic children but rises to 3 in 4 for Black children; cumulative receipt is also higher in nonmetropolitan counties than metropolitan counties. This study documents the reach of the existing social welfare system during the early childhood period, underlining the importance of race and space in twenty-first century America.
\end{abstract}

Keywords Early childhood $\cdot$ SNAP $\cdot$ TANF $\cdot$ Social welfare

Colleen Heflin

cmheflin@syr.edu

1 The Maxwell School of Syracuse University, 426 Eggers Hall, Syracuse, NY 13244-1020, USA 


\section{Introduction}

A well-established research tradition links family income to child wellbeing over the life course (Blau, 1999; Brooks-Gunn \& Duncan, 1997; Corcoran, 2001; Dahl \& Lochner, 2005; Guo \& Harris, 2000; Mayer, 1997; McLoyd, 1998; Reardon, 2011; Reardon \& Portilla, 2016; Smith et al., 1997). Evidence of an income effect seems to be strongest at the bottom of the income distribution, suggesting the strength of the relationship varies across incomes and presence of a threshold effect (Akee et al., 2010; Brooks-Gunn \& Duncan, 1997; Smith et al., 1997). Additional evidence suggests that the effect of income varies over the life course with the strongest impact on the cognitive development of preschool age children (Brooks-Gunn \& Duncan, 1997; Duncan et al., 1998, 2010, 2011). Consequently, many now argue for public investments to be made during the early childhood period when child-related expenses, such as childcare, are particularly high, and parental earnings are likely lower than earnings later in life.

Given the importance of early childhood for later life outcomes, the extant literature is surprisingly silent on social welfare program dynamics during this critical time of the life course. Furthermore, even less is known about the extent to which children of different racial and ethnic groups access social programs, or how patterns differ across metropolitan and nonmetropolitan contexts. In order to provide empirical information to guide conversations around structural inequality, we focus our lens on the Temporary Assistance for Needy Families Program (TANF) and the Supplemental Nutrition Assistance Program (SNAP), two federally funded means-tested programs administered at the state or county level that are designed to support basic needs and buffer the negative effects of childhood poverty. While there are other means-tested programs that offer support during childhood, such as WIC and school meals, as well as the Earned Income Tax Credit, we believe that TANF and SNAP deserve special consideration. TANF is specifically targeted at single-parent households with children, the family type that consistently faces the highest rates of poverty. SNAP, on the other hand, more broadly targets low-income households of all ages, but nonetheless serves a caseload in which $44 \%$ are children (Cronquist \& Lauffer, 2019). Furthermore, Rank and Hirschl (2009) estimate that from 1969 to 1997, half of all children resided in a household that participated in SNAP at some point during their childhood. Thus, given widespread program coverage during childhood, we focus our study on dynamics of program participation in SNAP and TANF during the first 6 years of life, the point in childhood when public investments are thought to have the highest rate of return (Heckman, 2006; Heckman et al., 2010).

We use administrative data from the Virginia Department of Social Services to document frequency and patterns of SNAP and TANF receipt during the birth to age six period for children born between 2007 and 2010 in the Commonwealth of Virginia. Specifically, we focus on the following research questions: (1) What are the participation dynamics in TANF and SNAP during early childhood? and (2) What is the cumulative level of program receipt over the first 6 years of life? For both questions, we document differences by race and ethnicity as well as 
by metropolitan and nonmetropolitan county residence, key axes of inequality in America. Together, we provide empirical evidence on the usage of two large federal programs designed to support low-income households during a period when children and their families are highly vulnerable, and document how these dynamics vary systematically across race and place.

This study makes several unique contributions to the literature. First, it provides more accurate estimates of longitudinal program participation over early childhood than what exists in the current literature through its use of state administrative data. Second, it provides estimates of program participation that reflect post 1996 Welfare Reform policy conditions and the 2008 Great Recession economic conditions and recovery. By focusing on the experience of children born between 2007 and 2010, our analysis provides a baseline for understanding how these programs may operate during the economic contraction caused by COVID-19. This study documents the reach of the existing social welfare system during the early childhood period, underlining the importance of race and space in twenty-first century America.

\section{Literature Review}

Poverty in the United States, particularly during childhood, is intertwined with race and space. For as long as the official poverty measure has been in usage, rates of poverty have been higher among black and Hispanic children than white children (Semega et al., 2020). In 2019, the latest year that national data are available, poverty among white non-Hispanic children was $8.9 \%$ versus $20.6 \%$ for Hispanic children (of any race) and $25.5 \%$ for black children. In addition, poverty in nonmetropolitan areas has consistently been higher than in metropolitan areas, although the gap has diminished over time (Semega et al., 2020). In 2019, metropolitan poverty was $10 \%^{1}$ and nonmetropolitan poverty $13.3 \%$ (Semega et al., 2020). Today, the risk of poverty during one's lifetime is highest during childhood. Older Americans used to have the highest rate of measured poverty before 1974 when policy choices (mainly the full adoption of Social Security and Supplemental Security Income) reduced poverty among the elderly. This suggests that targeted efforts to reduce poverty among vulnerable age groups can achieve those aims.

Negative consequences of childhood poverty are predicted by many different theoretical models across disciplinary traditions from life course theory in sociology (Elder, 1998), to human capital theory in economics (Becker, 1964), to ecological system theory in psychology (Bronfenbrenner, 1979). Each of these theoretical perspectives views the resources available during childhood, broadly construed, as inputs to later success across a broad range of adult outcomes, including education and earnings, cognitive, physical and mental health, and family and social connections. In particular, the life course perspective also acknowledges the importance of structural contexts, such as racial inequality and place. Our motivation for this

\footnotetext{
1 There is heterogeneity within US cities as well: Poverty within principal cities is higher (13.1\%) than in the suburbs around them (8.2\%) (Semega et al. 2020).
} 
study, then, is to examine how institutional structures, such as public policies, shape the public support received by young children, and how support differs by race and space during a crucial developmental period.

Historically, Aid to Dependent Children Program (AFDC) was the program most closely associated with cash support for low-income single-parent households during the early childhood period. However, due to concerns over work disincentives, patterns of long-term participation, and concerns about marriage disincentives, the Welfare Reform Act of 1996 replaced AFDC with the Temporary Assistance for Needy Families Program (TANF). Federal requirements for TANF imposed work requirements and 5-year lifetime limits on benefit receipt. In addition, TANF offered states greater flexibility to determine program eligibility, benefits, and services offered (Bitler \& Hoynes, 2016; Ziliak, 2016). States can divert federal TANF dollars to uses other than cash support. Consequently, national caseloads fell from 13 million AFDC recipients in 1995 to 2.25 million TANF recipients in 2018. The median cash benefit received dropped from bringing a family of three to 70 percent of the federal poverty line (FPL) in 1970 to $27 \%$ in 2020 (Safawi \& Floyd, 2020).

Previous research documents participation dynamics in AFDC using nationally representative survey data. ${ }^{2}$ However, post-Welfare Reform TANF participation dynamics are harder to study nationally both because number of TANF participants dropped considerably and state regulations differ on time limits, income and work requirements, and the services available. Instead, research tends to focus on the role of the economy and policy change in explaining declining state TANF caseloads (Council of Economic Advisers, 1997; Bartik \& Randall, 1999; Ziliak et al., 2000; Blank, 2001; Danielson \& Klerman, 2008), documenting TANF's declining share of the federal budget (Moffitt, 2013; Hoynes \& Schanzenbach, 2018), and evaluating the impact of welfare reform on a range of population-level outcomes (see Ziliak, 2016 for a review). In fact, some of the best research on individual participation dynamics in TANF after welfare reform uses qualitative methods and stresses that TANF plays little role in enabling poor single mothers to make ends meet (Shaefer \& Edin, 2013). Conversely, we know more about the composition of the TANF caseload. Nationally in FY2019, families in which the youngest child was five or below comprised half of the TANF caseload (United States Health and Human Services: Office of Family Assistance 2019); 37.3\% of the national caseload was comprised of recipients identified as Hispanic, $28.4 \%$ black, and $25.7 \%$ white (United States Health and Human Services: Office of Family Assistance, 2019). Nationally, average monthly participation rates for TANF were similar in metropolitan and nonmetropolitan counties from 2009 to 2012, the latest period for which estimates are publicly available (Irving \& Loveless, 2015).

Following the 1996 Welfare Reform Act, SNAP (formerly the Food Stamp Program) overtook TANF in expenditures per capita (Moffitt, 2013). The United States Department of Agriculture (USDA) funds SNAP to supplement household food security for those who qualify by providing a near-cash supplement to purchase food

\footnotetext{
${ }^{2}$ For example, Harris (1996) used a life table approach to document exit routes from welfare under AFDC program rules using the Panel Study of Income Dynamics (PSID).
} 
products. In 2019, SNAP provided nutrition support to 34 million Americans, with a total federal cost of $\$ 53.7$ billion (USDA 2020). Federal eligibility criteria require households to have a gross income below $130 \%$ of the FPL or be categorically eligible through participation in a specified program, such as TANF, to qualify for SNAP. While the basic eligibility rules and benefit amounts are set by the federal government, states administer SNAP at the state or county level (e.g., application process, recertification period, payment schedule). Therefore, there is substantial variation in SNAP policies across states. In 2018, USDA estimated that $84 \%$ of all eligible individuals participated in the program (Vigil, 2019).

An estimated 8.1 million children received food assistance through the SNAP program in 2017, representing $44 \%$ of all SNAP recipients nationally. Among children who received SNAP, about $29 \%$ were preschool aged or below (Cronquist \& Lauffer, 2019). Nationally, $19 \%$ to $29 \%$ of all children aged 0-4 received SNAP in 2016 (Schanzenbach \& Thorn, 2019). Black and Hispanic children are over-represented among the SNAP population: among child SNAP participants, 37\% were white, 30\% black, and 26\% Hispanic (any race) (Carlson et al., 2016). SNAP participation, like poverty, is higher in nonmetropolitan areas (Deb \& Gregory, 2016; Tiehen et al., 2012). From 2011 to 2016, 16\% of households in nonmetropolitan, and $13 \%$ of households in metropolitan areas participated in SNAP (FRAC, 2018).

Given the lower income eligibility requirement for TANF relative to SNAP, one would expect that that most TANF households would also receive SNAP. Newman et al. (2011) find that the association between SNAP and TANF receipt is positive, but the strength of this correlation has weakened over time. While about $80 \%$ of TANF families receive SNAP (United States Health and Human Services: Office of Family Assistance, 2019), only about $10 \%$ of SNAP households containing children also participated in TANF in 2017 (Cronquist \& Lauffer, 2019). ${ }^{3}$

Previous research on SNAP program participation dynamics over childhood is thin; Rank and Hirschl (2009) use the Panel Study of Income Dynamics (PSID) from 1968 and 1997, finding that about half of children lived in households reporting SNAP usage between the ages of 1 and 20 and one quarter by age five. For Black children, SNAP participation rates were higher- $90 \%$ by age 20 and $62 \%$ by age five. High rates of SNAP participation are consistent with the higher rates of Black childhood poverty and underline the importance of examining participation dynamics separately by race and space to better understand group-specific use of and access to governmental resources. ${ }^{4}$

Similar estimates of program participation over childhood are unavailable for TANF but, as noted above, there is considerable reason to expect that receipt is much lower post-Welfare Reform. TANF is time limited. In addition, SNAP is targeted at a much higher income distribution than TANF: federal eligibility for SNAP

\footnotetext{
3 We explore participation in different program bundles (SNAP alone, TANF alone, and SNAP+TANF) in Online Appendix Tables 1-3.

4 A recent contribution in this area is a report issued by the Public Policy Institute of California authored by Danielson et al. (2020) which take a similar approach to the current study with a focus on the 2012 birth cohort using California administrative data.
} 
is at $130 \%$ of the FPL (or higher in states that have broad based categorical eligibility), while TANF is typically thought to reach those below $50 \%$ of the FPL. In addition, in 33 states including Virginia, the maximum benefit amount for SNAP is actually higher than that of TANF.

This study makes an important contribution to the literature by documenting participation in SNAP and TANF over the early childhood period using state administrative data. What is currently known about social program participation over early childhood does not reflect current economic and policy conditions, and likely understates participation rates due to growing levels of self-reported false negatives in social programs such as SNAP (Meyer et al., 2015, 2018). This study documents how children interact with the two largest means-tested programs in the social safety net over the early childhood period, when they are likely to benefit most from the public investment. Finally, we explore how patterns of participation differ by two important axes of inequality, race and county metropolitan status.

Based on previous research in this area, we expect to find that structural differences in the program design result in SNAP supporting many more children during early childhood than TANF and that the number of years of the program support received during the early childhood period will be longer for SNAP than for TANF. Given higher poverty rates among black and Hispanic children than among whites, we expect higher levels of participation in both programs, although differences in need will be mediated by language and knowledge barriers, immigration status, and social stigma across racial and ethnic groups. In addition, given the stronger economic conditions in metropolitan areas, we expect lower rates of participation in SNAP and TANF relative to nonmetropolitan areas.

\section{Background on Virginia}

From 2014 to 2018, 32.4\% of Virginia's children lived in low-income families (below 200\% of the FPL) using American Community Survey 5-year estimates. The Commonwealth's demographic composition and economy are roughly comparable to the national average. About half (53\%) of Virginia's young children are white, with another 19\% Black and 14\% Hispanic (National Center for Children in Poverty, 2018). Virginia contains rural, suburban, and urban communities. 53 of Virginia's county equivalents (counties and independent cities) are nonmetropolitan, and 81 are metropolitan using the USDA's rural classification. Economically, the timing of Virginia's contractions and expansions have mirrored those in the rest of the country. As of December 2019, the state unemployment rate was below 3.0\%.

TANF served 33,595 individuals on 15,483 cases in Virginia in October 2020 (VDSS, 2020), which is down from 184,000 prior to Welfare Reform in 1995 (Office of Family Assistance 2004). Lifetime program receipt is limited to 60 months, with individual spells limited to 24 months followed by a 24 -month waiting period before receipt can begin again. Program eligibility is limited to US citizens or eligible immigrants with monthly incomes below $\$ 546-776$, or $30-42 \%$ of the FPL, (depending on the county of residence) for a family of three in 2020. According to state analysis of program participation dynamics, most participation spells last for 
less than 1 year in total with most participants not cycling on and off the program (Irving \& Loveless, 2015; VDSS, 2012). Receipt is contingent upon $30 \mathrm{~h}$ of qualified work activity unless the parents have received a health-related exemption, are in their third trimester of pregnancy, or are caring for an infant under 12 months old. Recipients may receive a $\$ 100$ child support pass through as well as an additional $\$ 50$ per month for 12 months transitional benefit after participation in the Virginia Initiative for Employment not Welfare (VIEW), the state job training program. Virginia is one of a handful of states that imposes a family cap, meaning that the benefit size does not increase if the family size increases after 9 months of the date of first receipt. As such, TANF policies in Virginia are a combination of both more restrictive and more generous than the average state, with a clear orientation towards the "Work First" approach. Finally, the size of TANF benefits depends on Virginia clients' region of residence and the maximum benefit for a mother with two children ranged from $\$ 363$ to $\$ 442$ in 2019 (VDSS, 2019).

SNAP in Virginia has wider reach; approximately 655,000 individuals living in 319,000 households received \$1.0 billion in SNAP benefits in FY2019 (FNS, 2020). When given the option, Virginia has chosen policies that tend to limit the accessibility and generosity of SNAP. For example, Virginia is one of only ten states that does not extend eligibility of SNAP to households with gross household incomes above $130 \%$ of the FPL based on categorical eligibility with other programs. It is also one of the few to impose a modified drug felony ban on benefits. Finally, it does not allow non-custodial parents paying child support to deduct the value of their child support payments from their gross income at the point of eligibility determination. Because of these policies, fewer households are eligible for SNAP benefits in Virginia than in comparable states and eligible households are less likely to participate (76 versus the national average of 84\% in FY2017) (Cunnyngham, 2020).

Virginia allows households to apply for SNAP and TANF jointly in some cases and uses consistent indicators of household resources to determine eligibility for both. Furthermore, if a TANF household head fails to comply with work requirements, the entire household can lose SNAP benefits. Together, these policies likely result in Virginia serving a somewhat smaller TANF and SNAP population than in states with more generous state policies and suggest that our results may provide an underestimate of the reach of these programs in other states. ${ }^{5}$ Virginia has significant racial/ethnic and metropolitan/nonmetropolitan diversity, providing a useful case study to examine the extent to which families with children access means-tested federal programs during early childhood.

\footnotetext{
5 For example, recent work by Danielson et al (2020) reports that rates of participation in California's TANF program are much higher during early childhood than what we report for Virginia.
} 


\section{Data}

We use administrative data from the Virginia Department of Social Services to document patterns in program participation in SNAP and TANF during the first 6 years of life. We observe the population of children born between 2007 and 2010 who participated in either social program (195,834 children in all who participate between year of birth and year of fifth birthday). ${ }^{6}$ Our administrative data allow us to observe the year and county of program receipt as well as basic demographic information for the child (race and ethnicity, age, and sex), for the household head (race and ethnicity, age, marital status, and education, county of residence), and household composition (number and ages of other children; number and ages of adults). This allows us to create complete social program life histories for all residents of Virginia during our observation period; we focus on those in early childhood.

Using statewide administrative datasets to document social welfare participation during early childhood has several advantages over the survey data approach used to inform past estimates. First, it has been well established that recipients of social programs, such as SNAP and TANF, often incorrectly report non-participation (Meyer et al., 2015); as many as 1 in 2 SNAP recipients falsely report not receiving program benefits in the previous year when responding to the Current Population Survey (Celhay et al., 2018; Meyer et al., 2018) with significant consequences for studies of poverty and social welfare receipt (Bollinger \& David, 1997; Meyer \& Mittag, 2019; Meyer et al., 2018). Second, the high level of misreporting found in crosssectional estimates of social program participation is likely amplified in longitudinal survey data since data collection for current longitudinal panel datasets such as the PSID and the Early Childhood Longitudinal Study are now fielded every other year. Finally, levels of SNAP and TANF participation have shifted in opposite directions in the last 20 years, with TANF participation plummeting after the 1996 Welfare Reform Act and SNAP participation increasing dramatically after the Great Recession, rendering previous estimates of cumulative participation inaccurate guideposts for recent cohorts of children.

\section{Methods}

We document recent patterns of social program participation, using four birth cohorts of children in the Commonwealth of Virginia and a life table technique to describe participation dynamics and timing, breakdowns by race and ethnicity, and

\footnotetext{
6 While the analytic population for our analysis contains all children from these cohorts who use SNAP and TANF during their early childhood period, we consider this a sample of potential social services recipients in a state like Virginia during a period like the one examined. That is, in addition to documenting differences in raw means for the Commonwealth's SNAP and TANF participants, we use statistical inference for results presented in Online Appendix Tables 1-3 to determine which of the documented patterns are due to true differences between groups rather than other observed and unobserved features of the members of those groups in our sample.
} 
breakdowns by county metropolitan status. ${ }^{7}$ Essentially, we observe program participation in TANF and SNAP for each year of life, focusing our lens on the early childhood period, from birth to age six. For each calendar year, we observe if the child received program benefits, and we add these events together to calculate the cumulative proportion of years observed in each program.

One advantage of our administrative data approach to this question is that we have a large sample size. While Rank and Hirschl (2009) pooled data from the PSID across 30 years to be able to observe 10,000 5 year olds, we substantially exceed that sample size with data from a single cohort. ${ }^{8}$ This allows us to achieve both greater precision with our estimates and greater external validity for current conditions, because our estimates derive from a much more tightly constrained and relevant period. All children contribute up to six person-years to the life table entering at birth and leaving at age 6 .

While we do not observe Virginia children who do not participate in SNAP or TANF, we know the size of the annual birth cohort from the National Center for Health Statistics, Division of Vital Statistics. We then bound our estimates for cumulative receipts using two strategies. First, for our upper bound estimates, we assume that the birth cohort is the relevant population size. Doing so requires assumptions about the number of deaths, immigration, and migration to and from the state. For simplicity, we assume that immigration to the state balances deaths and emigration. On the one hand, given that childhood deaths are highest in the first year of life and that people tend to move less (and less far) during economic downturns (Stoll, 2013), this likely biases our estimates of the proportion of children who receive SNAP or TANF in each year of life downward. On the other hand, the population of young children who ever live in Virginia in early childhood is larger than those born there, so our estimates of any participation in the period before age 6 could be biased upward depending on enrollment and persistence patterns in SNAP and TANF among more transient children. However, given the ages when number of participants peaks, the magnitude of the bias is likely to be small. ${ }^{9}$

We then assess robustness to the potential bias empirically, inflating our birth cohort by the estimated share of 5-year-old children living in Virginia who were

\footnotetext{
7 We assess the sensitivity of our results to alternative measures of metropolitan status, replicating our analysis using three groups based on NCHS categories: (1) 48 counties in large metropolitan areas (greater than 1 million in population); (2) 41 counties in micropolitan to medium metropolitan areas (10,000-1 million in population); (3) 46 counties in noncore areas (less than 10,000 in population). Results are available from the authors upon request and are largely consistent with those shown here. We find substantial differences in timing of SNAP participation between large metropolitan counties as compared to the other two groups. For TANF, the results are more muted, with differences between the three geographic classifications no greater than 2 percentage points at any age. Results are available in Online Appendix Table 4.

8 Rank and Hirschl (2009) pool information on children over 30 years to yield approximately 90,000 child-year observations; approximately 10,000 are observed at age 5. In contrast, we use administrative data on 195,834 unique children in four birth cohorts who are observed over a 6-year period, providing 900,000 child years of data.

9 Danielson et al (2020) report that about $10 \%$ of 5-year-olds in California were born out of state. If we assume the same level of in-migration in Virginia, our estimates have a small (less than 5 percentage point) upward bias.
} 
born outside the Commonwealth. Here, we apply a method proposed in Danielson et al. (2020; Technical Appendix B), estimating the relevant cohort size in the year children turn five using Single Year of Age County Population Estimates data from the Surveillance, Epidemiology, and End Results Program (SEER) and then estimating the share of children living in Virginia at that age who were born out of state using the Census Bureau's American Community Survey microdata prepared for the Integrated Public Use Microdata Series (IPUMS-USA). By adding the live birth count to the estimated born out of state count, we can estimate the share of children who live in Virginia at any time between birth and the year they turn five who participate in Virginia SNAP or Virginia TANF during this time in their life. These estimates provide lower bounds of cumulative participation, because while we offer a reasonable estimate of the total cohort size, we only capture SNAP or TANF receipt for years that population lives in Virginia (ignoring SNAP or TANF receipt in other localities, including nearby District of Columbia, Maryland, West Virginia, North Carolina, etc.) As a result, estimates of participation in a particular year of life provide one set of lower bound estimates, estimates of any participation in early childhood compared to migration-adjusted cohort sizes provide an alternative set of lower bound estimates, and estimates of any participation in early childhood compared to live birth counts provide upper bound estimates of SNAP and TANF uptake.

Our analysis proceeds in two parts. First, we document patterns of participation over early childhood for participants of SNAP and TANF, describing the differences in the timing and duration of participation and how these program dynamics differ by race and ethnicity of the child ${ }^{10}$ and metropolitan county residence. Second, we estimate the cumulative level of participation in both the SNAP and TANF programs over the first 6 years of life, before most children enter the public school system, for four cohorts of children growing up during the Great Recession and the early economic recovery. In the online appendix, we present analyses that document differences in program participation between children who receive TANF only, SNAP only, and both SNAP and TANF.

\section{Results}

\section{The Timing of SNAP and TANF Participation During Early Childhood}

We begin by examining the ages at which young children are in a SNAP or TANF household in Table 1 . We observe that the number of children who first participate

\footnotetext{
10 We construct five mutually exclusive race and ethnicity categories: Hispanic, Non-Hispanic White, Non-Hispanic Black, Non-Hispanic Other, and Missing Race. Individuals who are of Hispanic ethnicity are categorized as Hispanic regardless of their identified race. "Non-Hispanic Other Race" includes individuals who are Asian, Native American, Hawaiian, or are categorized as "other race" but are not Hispanic. Non-Hispanic biracial individuals are categorized as Non-Hispanic Black if they are partially black, and Non-Hispanic Other otherwise. Individuals who are not identified as Hispanic and for whom the administrative record has no recorded race, are categorized as "Missing."
} 
Table 1 Age first participated in SNAP and TANF (2007-2010 birth cohorts)

\begin{tabular}{|c|c|c|c|c|c|c|c|}
\hline & \multicolumn{7}{|c|}{ \# Participating by age } \\
\hline & 0 & 1 & 2 & 3 & 4 & 5 & 6 \\
\hline \multicolumn{8}{|c|}{ Panel A: SNAP } \\
\hline \multicolumn{8}{|c|}{ Age first participated } \\
\hline 0 & 88,234 & 82,087 & 72,816 & 68,824 & 65,311 & 61,852 & 56,608 \\
\hline 1 & & 46,162 & 40,773 & 34,771 & 31,864 & 29,650 & 26,740 \\
\hline 2 & & & 21,821 & 18,959 & 14,522 & 12,654 & 10,908 \\
\hline 3 & & & & 15,728 & 13,366 & 9813 & 7988 \\
\hline 4 & & & & & 12,371 & 10,227 & 7008 \\
\hline 5 & & & & & & 10,663 & 8582 \\
\hline 6 & & & & & & & 7073 \\
\hline Total & 88,234 & 128,249 & 135,410 & 138,282 & 137,434 & 134,859 & 124,907 \\
\hline \multicolumn{8}{|c|}{ Panel B: TANF } \\
\hline \multicolumn{8}{|c|}{ Age first participated } \\
\hline 0 & 22,791 & 18,980 & 13,233 & 10,319 & 7263 & 5981 & 5030 \\
\hline 1 & & 17,929 & 13,159 & 9009 & 6131 & 4436 & 3697 \\
\hline 2 & & & 10,769 & 7629 & 4797 & 2911 & 1960 \\
\hline 3 & & & & 7361 & 5035 & 2986 & 1616 \\
\hline 4 & & & & & 5421 & 3506 & 1864 \\
\hline 5 & & & & & & 4466 & 2723 \\
\hline 6 & & & & & & & 2769 \\
\hline Total & 22,791 & 36,909 & 37,161 & 34,318 & 28,647 & 24,286 & 19,659 \\
\hline
\end{tabular}

Authors' tabulations based on Department of Social Service Administrative Data from Virginia

decreases monotonically each year from year of birth to the year they turn six for both SNAP (shown in the top panel) and TANF (shown in the bottom panel). For participants in both programs, by far the largest number of children begin receiving social welfare in the year of their birth, as shown in the first row of each panel. This pattern is consistent with what we know about new births pushing female-headed households into poverty (McKernan \& Ratcliffe, 2002). For SNAP, about half as many children receive their first benefits in the year of their first birthday relative to the number of new children receiving SNAP in the year of their birth. Even fewer children begin SNAP in the year they turn two (less than $25 \%$ of the number who begin in the year they are born). The number of new cases continues to fall from there; for example, the number of children beginning SNAP after their fifth birthday is approximately $1 / 9$ that of the year of birth.

For TANF, the decline in children by age of first participation is much less dramatic than that for SNAP. The number of new entrances onto TANF for children turning two is about half the number who first participate in the year of birth (it takes only 1 year for the number of new SNAP participants to fall that precipitously). The number does not fall to $25 \%$ of the birth year count of new cases until the year children turn four (as compared to the year children turn two for SNAP). 
Table 1 also displays the age during early childhood in which the most children participate in each social welfare program (see row totals). For SNAP, participation peaks around ages 3-4 while the peak in TANF participation is a full year earlier around ages 2-3. This pattern is consistent with the Virginia requirement for adults to leave TANF for 24 months after 24 months of receipt. Additionally, while participation does decline in the year children turn six (the first year for which most students are enrolled in school the entire calendar year and a point when expectations for mothers to work increases), it does not drop dramatically. Most likely, this is largely because over half $(56.7 \%)$ of 6 year olds who receive SNAP or TANF have a younger child in the household. In addition, about $8.5 \%$ of children in Virginia live in a school district that only offers half-day kindergarten (Kindergarten Instructional Time 2020).

Finally, Table 1 also illustrates the reach of SNAP and TANF during early childhood. While SNAP is not designed primarily as an early childhood intervention to support young families, it currently reaches nearly three times more children than TANF under pre-COVID-19 conditions: For the 2007 to 2010 birth cohorts in Virginia, 202,052 unique children participated in SNAP in at least 1 year between their year of birth and the year they turn six (194,979 of which participate between birth and five). TANF, the program traditionally associated with aiding households with young children, however, reached only 71,506 unique children $(68,737$ between birth and five). Furthermore, given the high number of children who began receiving SNAP in their year of birth, SNAP reached a high number of postpartum mothers and infants, a population that is often not articulated as a specific target of the program. ${ }^{11}$

\section{The Persistence of SNAP and TANF Participation During Early Childhood}

Table 2 presents the share of children persisting in SNAP and TANF by age first on the program. ${ }^{12}$ Children who begin receiving SNAP earlier persist on SNAP longer, which can be observed by examining the diagonal in Table 2. For example, 93\% of children who first receive SNAP in their birth year persist to the year they turn one, while only $85 \%$ of children who first receive SNAP in the year they turn three persist to the year they turn four. Similarly, among children who first receive SNAP in the year they turn one, $75 \%$ also receive SNAP 2 years later when turning three, but among children who first receive SNAP in the year they turn three, only $62 \%$ persist on SNAP 2 years later in the year they turn five. Thus, throughout early childhood, the age of first receipt of SNAP is strongly correlated with more years of annual participation in the program.

Persistence is lower for TANF than SNAP, as expected since TANF receipt is time limited. For example, the share of children who persist on TANF after 1 year

\footnotetext{
11 High enrollment for this group may well be due to joint participation in other programs that target prenatal and postnatal participation of mothers and infants, such as Medicaid, CHIP, or the Special Supplemental Nutrition Program for Women, Infants and Children Program (WIC).

12 We note, however that since we cannot observe monthly participation, program participation may not be continuous, and our measure of persistence includes households that leave and return to the program. We also reproduce Table 2 for each racial and ethnic group in Table 3.
} 
Table 2 Share in SNAP and TANF (2007-2010 birth cohorts)

\begin{tabular}{|c|c|c|c|c|c|c|c|}
\hline & \multicolumn{7}{|c|}{ Share participating by age/age first participated } \\
\hline & $0(\%)$ & $1(\%)$ & $2(\%)$ & $3(\%)$ & $4(\%)$ & $5(\%)$ & $6(\%)$ \\
\hline \multicolumn{8}{|c|}{ Panel A: SNAP } \\
\hline \multicolumn{8}{|c|}{ Age first participated } \\
\hline 0 & 100 & 93 & 83 & 78 & 74 & 70 & 64 \\
\hline 1 & & 100 & 88 & 75 & 69 & 64 & 58 \\
\hline 2 & & & 100 & 87 & 67 & 58 & 50 \\
\hline 3 & & & & 100 & 85 & 62 & 51 \\
\hline 4 & & & & & 100 & 83 & 57 \\
\hline 5 & & & & & & 100 & 80 \\
\hline 6 & & & & & & & 100 \\
\hline \multicolumn{8}{|c|}{ Panel B: TANF } \\
\hline \multicolumn{8}{|c|}{ Age first participated } \\
\hline 0 & 100 & 83 & 58 & 45 & 32 & 26 & 22 \\
\hline 1 & & 100 & 73 & 50 & 34 & 25 & 21 \\
\hline 2 & & & 100 & 71 & 45 & 27 & 18 \\
\hline 3 & & & & 100 & 68 & 41 & 22 \\
\hline 4 & & & & & 100 & 65 & 34 \\
\hline 5 & & & & & & 100 & 61 \\
\hline 6 & & & & & & & 100 \\
\hline
\end{tabular}

is 10-20 percentage points lower relative to that of SNAP at all ages of first receipt. However, children who first receive TANF at earlier ages are still more likely to persist relative to children who first receive TANF at older ages, despite time limits. Of those on TANF in their year of birth, 1 in 3 also receive TANF benefits 4 years later in the year they turn four; of those who first receive TANF in the year they turn two, less than 1 in 5 receive TANF 4 years later at age six. It is noteworthy, however that for TANF, the "persistence" observed in Table 2 does not reflect consistent participation in most cases, instead containing gaps between periods of receipt due to the 24-month time limit and 24-month waiting period requirements, gaps which we sometimes do not observe precisely due to our use of annual participation data.

In order to document racial differences in the relationship to these two programs, Fig. 1 presents the racial and ethnic composition (Black, Hispanic, White) of new entrants to SNAP and TANF, respectively, by age of first entrance. There are both differences between programs and across racial groups for age of first participation. For SNAP, nearly half of the caseload that enters in the birth year is composed of Black children, the highest share of participants for this age among the racial groups. However, in the year children turn two, the proportion of Black new entrants to SNAP is closer to $30 \%$ of total new cases for that age and virtually indistinguishable from that of Hispanic children; instead, the greatest share of new entrants is composed of White children. In contrast, at all ages, new entrants to TANF are most frequently Black and least frequently Hispanic; White children fall in between the 
Panel A Age First on SNAP

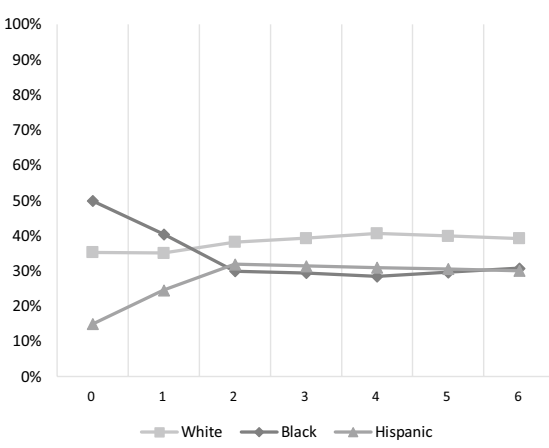

Panel B Age First on TANF

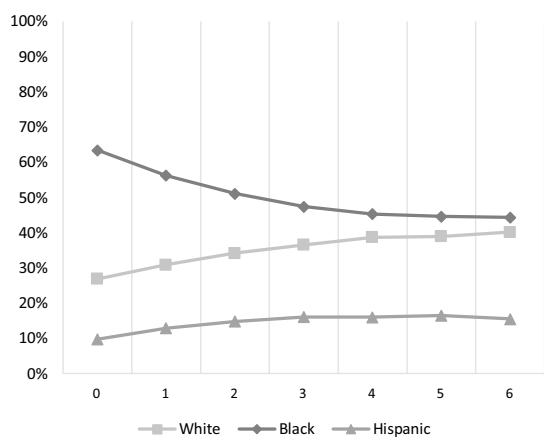

Fig. 1 Age first on program by race and ethnicity

other two groups, although the gap between White and Black children nearly closes by age 3 .

Figure 2 shows the racial breakdown of the SNAP and TANF caseloads at each age, respectively. Given the relationship between persistence and the racial distribution of first entrance at birth, it is perhaps no surprise that Black children comprise the largest share of the caseload at each age, followed by White children and then Hispanics. However, Black children comprise a larger share of the TANF caseload than the SNAP caseload, while White and Hispanic children comprise a larger share of the SNAP caseload relative to the TANF caseload. These racial patterns of program participation over early childhood likely reflect different levels of deep poverty, program knowledge, and fear of social stigma or legal repercussions (especially for Hispanic mixed status families) that structure childhood poverty in racially disparate ways.

When we turn to county metropolitan status, our results document similar trends across county designations, despite the differences in demographic composition and the size of the TANF cash benefit available to residents of different counties. Similar breakdowns (as shown by race and ethnicity above) are shown in Figs. 3 and 4 by
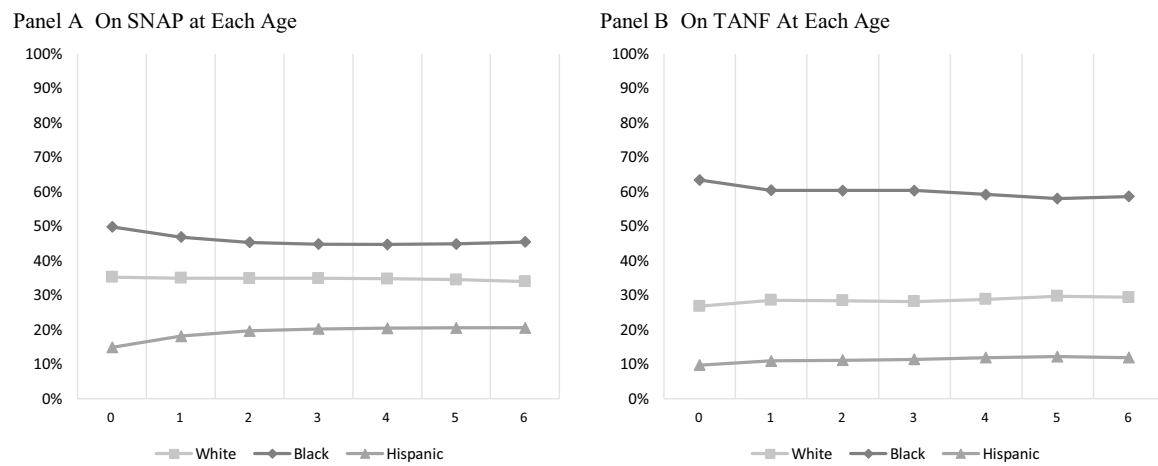

Fig. 2 On program at each age by race and ethnicity 

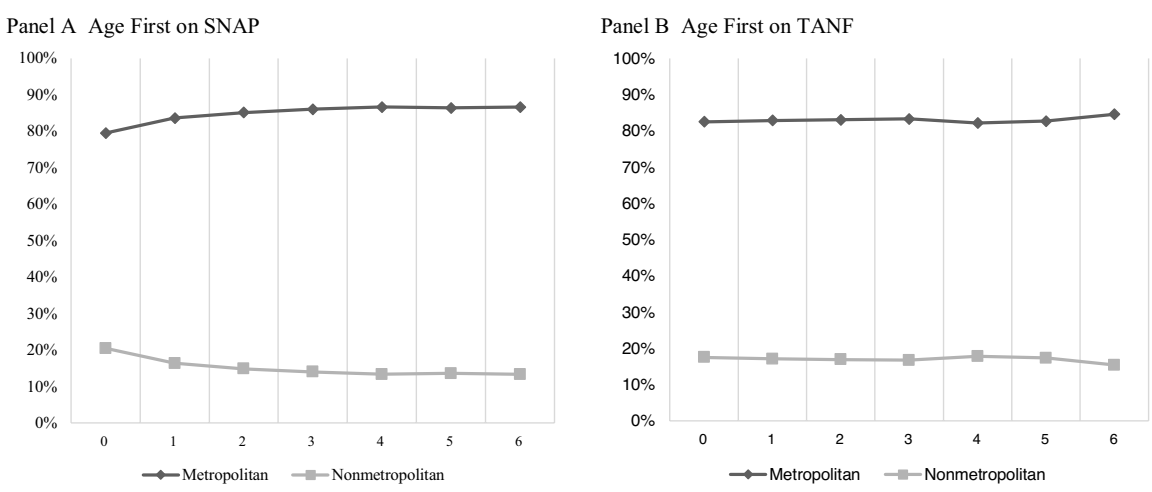

Fig. 3 Age first on program by county of residence metropolitan designation
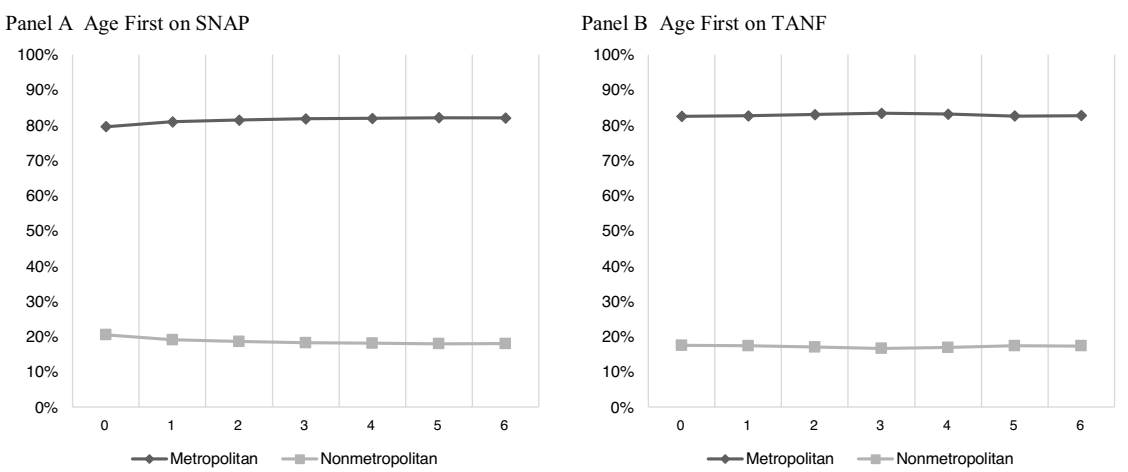

Fig. 4 On program at each age by county of residence metropolitan designation

county metropolitan/nonmetropolitan designation. Approximately $80 \%$ of children in SNAP and TANF households live in metropolitan counties with a slightly higher proportion coming from nonmetropolitan areas in the birth year. However, in 2018, $90.6 \%$ of children less than 1 years old resided in metropolitan counties; children living in nonmetropolitan counties are over-represented in both TANF and SNAP. We interpret higher program participation levels in nonmetropolitan areas as, once again, reflecting spatial structural inequality experienced during early childhood.

\section{Kindergartners' Age of First SNAP and TANF Participation}

In Table 3, we extend our analyses by reporting the share of 6-year-old SNAP or TANF participants (when most students are enrolled in school) by age of first participation. Overall, a high share of children observed to participate in SNAP in the year they turn six-received SNAP for many more years than just that one. This results from both higher numbers of first-time SNAP recipients at younger ages (as shown 
Table 3 Kindergarten participation in SNAP and TANF (2007-2010 Birth Cohorts)

\begin{tabular}{|c|c|c|c|c|c|c|c|}
\hline \multirow{3}{*}{$\begin{array}{l}\text { Panel A: } \\
\text { SNAP }\end{array}$} & \multicolumn{7}{|c|}{ Share of 6-year-old participants by age of 1 st receipt } \\
\hline & \multicolumn{5}{|c|}{ Child race or ethnicity } & \multicolumn{2}{|c|}{ County of residence } \\
\hline & & All (\%) & White (\%) & Black (\%) & $\begin{array}{l}\text { Hispanic } \\
(\%)\end{array}$ & $\begin{array}{l}\text { Metropoli- } \\
\tan (\%)\end{array}$ & $\begin{array}{l}\text { Nonmetro- } \\
\text { politan (\%) }\end{array}$ \\
\hline \multirow{7}{*}{$\begin{array}{l}\text { Age first } \\
\text { partici- } \\
\text { pated }\end{array}$} & 0 & 45 & 47 & 59 & 31 & 43 & 54 \\
\hline & 1 & 21 & 22 & 23 & 24 & 22 & 20 \\
\hline & 2 & 9 & 9 & 6 & 15 & 9 & 7 \\
\hline & 3 & 6 & 7 & 4 & 10 & 7 & 5 \\
\hline & 4 & 6 & 6 & 3 & 8 & 6 & 4 \\
\hline & 5 & 7 & 6 & 3 & 8 & 7 & 5 \\
\hline & 6 & 6 & 4 & 2 & 5 & 6 & 4 \\
\hline \multirow{3}{*}{$\begin{array}{l}\text { Panel B: } \\
\text { TANF }\end{array}$} & \multicolumn{7}{|c|}{ Share of 6-Year-Old Participants By Age of 1st Receipt } \\
\hline & \multicolumn{5}{|c|}{ Child race or ethnicity } & \multicolumn{2}{|c|}{ County of residence } \\
\hline & & All (\%) & White $(\%)$ & Black $(\%)$ & $\begin{array}{l}\text { Hispanic } \\
(\%)\end{array}$ & $\begin{array}{l}\text { Metropoli- } \\
\tan (\%)\end{array}$ & $\begin{array}{l}\text { Nonmetro- } \\
\text { politan }(\%)\end{array}$ \\
\hline \multirow{7}{*}{$\begin{array}{l}\text { Age first } \\
\text { partici- } \\
\text { pated }\end{array}$} & 0 & 26 & 20 & 34 & 19 & 25 & 27 \\
\hline & 1 & 19 & 18 & 22 & 18 & 19 & 19 \\
\hline & 2 & 10 & 11 & 10 & 11 & 10 & 10 \\
\hline & 3 & 8 & 9 & 8 & 11 & 8 & 8 \\
\hline & 4 & 9 & 11 & 8 & 11 & 9 & 10 \\
\hline & 5 & 14 & 16 & 10 & 16 & 14 & 14 \\
\hline & 6 & 14 & 15 & 8 & 15 & 14 & 12 \\
\hline
\end{tabular}

in Table 1) and greater persistence among children who enter earlier (as shown in Table 2). For example, about $64 \%$ of children who received SNAP in their birth year also receive SNAP in the year they turn six. ${ }^{13}$ As a result, for 6-year-old children, school officials observe the tip of the iceberg of early childhood poverty and social welfare participation because many more years of SNAP participation are hidden from their view and not observed by school administrators and teachers when students enter school. As shown in Table 3, 45\% of children on SNAP in the year they turn six first received SNAP in their year of birth; $21 \%$ first received SNAP in the year they turned 1; $9 \%$ first received SNAP in the year they turned 2; and about $6 \%$ received SNAP for the first time in each year between ages three and six.

If one focuses on the participation histories of 6-year-old children on TANF, 26\% first received TANF in their birth year; 19\% first received TANF in the year they turn one, $10 \%$ in the year they turn two, and about $8 \%$ in the years that they turn age three or four. Despite the fact that TANF has strong incentives towards shorter lifetime periods of receipt, but perhaps because Virginia requires intermittent participation,

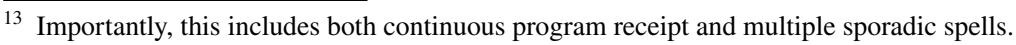


among all 6-year-olds on TANF, only $14 \%$ went on TANF for the first time in the previous year, and $14 \%$ for the first time at age six; these levels are low, but still much higher than for SNAP.

Racial and spatial differences once again document the structural inequality experienced during the early childhood period. For children receiving SNAP at age 6, $69 \%$ of white children, $82 \%$ of black children, and $55 \%$ of Hispanic children first received SNAP in their first 2 years of life. Similarly, $74 \%$ of children in nonmetropolitan counties but only $65 \%$ of children in metropolitan counties who participate in SNAP in their kindergarten year first participated in their first 2 years of life. While early TANF participation is less common than for SNAP, $45 \%$ overall among children in kindergarten, the racial patterns are consistent with those of SNAP: black children on TANF at age 6 are much more likely to have first participated in SNAP in the first 2 years of life compared to both white and Hispanic children. Interestingly, among children participating in TANF in their kindergarten year, there are no apparent differences in timing of first TANF receipt by metro status, despite the differences in SNAP.

\section{Cumulative Participation over Early Childhood}

Finally, we document how many unique children participate in SNAP or TANF. See Table 4. Given that between 103,000 and 109,000 live births occurred each year during our study period, ${ }^{14}$ we can estimate the proportion of children born in Virginia who receive SNAP or TANF in their birth year, 5 years later, and cumulatively over the first 6 years of life. We then adjust the birth cohort size to make it robust to in- and out-migration to and from the Commonwealth (using a methodology introduced in Danielson et al., 2020), in order to estimate the share of all children who live in Virginia between birth and the fifth year of life who receive SNAP or TANF benefits from the Commonwealth of Virginia during that period. We find that about 1 in 5 children in Virginia receive SNAP or TANF in their year of birth (column 5). However, important variation exists across race and space. While only $11.85 \%$ of white children receive SNAP or TANF in their birth year, 22\% of Hispanic and $45 \%$ of black children live in families that receive support from these programs. Furthermore, $19.2 \%$ of children in metropolitan counties, but $37.8 \%$ of children in nonmetropolitan counties, participate in SNAP and TANF in their year of birth.

Much higher shares of children participate in TANF and SNAP in the calendar year they are likely to enter kindergarten (YOB + 5) than in their year of birth. Column 6 shows that about 1 in 3 children receive SNAP or TANF in their kindergarten year $(\mathrm{YOB}+5)$ and that shares vary by race and space. Still, when schools use observed participation in social programs in the year of school entry, they might miss interactions with social services that children experienced earlier in early childhood.

\footnotetext{
${ }^{14}$ The later years have the lower levels of births as fertility dropped during the Great Recession as documented by Hamilton et al. (2020).
} 


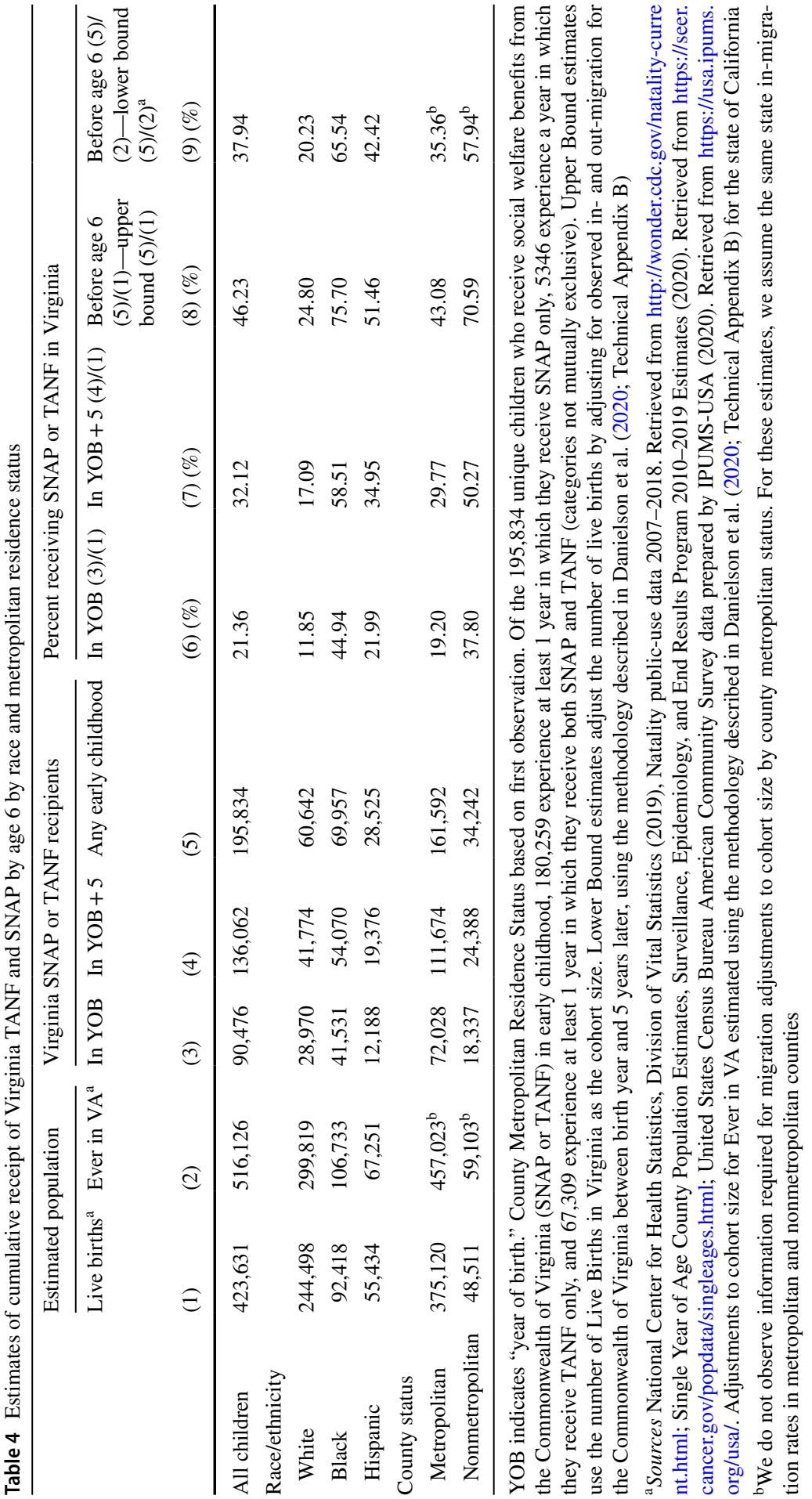


We next calculate cumulative receipt, conducting the same life table calculation as Rank and Hirschl (2009) for the first 6 years of life, and providing upper and lower bound estimates by calculating as a share of live births and as a share of estimate total number of children who live in the state during this period (inflating the live birth with our estimates of migration into the state). Using live births as our estimate of cohort size, we find that $46.23 \%$ of children participated in SNAP or TANF in the first 6 years of life in Virginia. This estimate is considerably larger than the Rank and Hirschel estimate of $25 \%$ for early childhood from the PSID, ${ }^{15}$ which is likely the result of more accurate reporting of program participation as well as high overall levels of participation during the Great Recession and early recovery period, including policy conditions designed to increase participation. Even our lower bound estimate, which compares cumulative participation in Virginia SNAP or TANF to the estimated number of children who spent any year from their birth year to 5 years later of their birth to age five period, suggests much higher participation rates than Rank and Hirschel (37.94\% versus 25\%). In addition, Rank and Hirschl estimate participation in SNAP alone but our estimate includes TANF participation, as well. However, as the notes to Table 4 illustrate, most children live in households that receive program bundles that include SNAP and only a small fraction receive TANF alone. Removing the TANF only households from our calculation, decreases estimated levels of participation trivially $(42.55 \%$ and $34.93 \%$ for upper and lower bound estimates, respectively). Thus, estimated cumulative receipt is substantially greater than estimates of participation during individual years.

Table 4 also presents estimates of cumulative early childhood receipt of SNAP and TANF by race and ethnicity. Racial estimates are once again in line with those documented by Rank and Hirschl (2009) but are substantially greater, consistent with our finding for all children. About half of all Hispanic children in Virginia are observed receiving SNAP or TANF in early childhood (51.46\% and $42.42 \%$ for upper and lower bounds, respectively). For Black children, the share of children who participate at some point in early childhood is much higher than Hispanic children, at between 65.54 and $75.70 \%$. In stark contrast, share of White children is just 20.23-24.80\%.

Finally, we present cumulative receipt estimates for TANF and SNAP by metropolitan county status in Table 4 (assigning children to the counties in which we first observe them). Children in metropolitan counties have much lower cumulative levels of social welfare receipt over the early childhood period than do children in nonmetropolitan counties. Specifically, our upper bound estimates indicate that $43.08 \%$ of children in metropolitan counties receive SNAP and TANF in the first six calendar years of life compared to $70.59 \%$ of children in nonmetropolitan counties. ${ }^{16}$ In order to apply migration adjustments to estimate the lower bound participation rates

\footnotetext{
15 And more in line with recent estimates using administrative data from California by Danielson et al. (2020).

16 As a sensitivity check, we calculated the cumulative receipt for those only observed in metropolitan counties and those only in nonmetropolitan counties; by construction, these are also lower bound estimates because the number of live births is the same, but we only include those who receive their benefits
} 
by metropolitan county status, we must assume that children migrate into the state at the same rate in metropolitan and nonmetropolitan counties (we do not observe instate migration for every county). Doing so yields slightly lower participation rates in both types of counties (35.36\% and $57.94 \%$ for metropolitan and nonmetropolitan, respectively).

\section{Discussion}

We use administrative data from a large and diverse state to document verified program participation in SNAP and TANF during the early childhood period, which we define here as birth to age six, when all children in Virginia are eligible to be enrolled in the public school system. Previous research has shown that during the early childhood period, poverty is likely to have long-term negative consequences and investments are likely to have the highest social return. We chose to focus on SNAP and TANF program participation because they represent a substantial portion of the social safety net available to families with young children.

We find that during the early childhood period, participation in SNAP is about four times greater than that of TANF and that most children begin their connection with the social welfare system in their birth year. Children who participate earlier in life tend to stay connected over a longer portion of the early childhood period, although SNAP participation peaks around ages 3-4 while TANF peaks earlier, around ages 2-3. Finally, over the early childhood period, on average, just under 1 in 2 children in Virginia participated in SNAP or TANF but demography plays an important role in this process: The level of cumulative receipt is only 1 in 4 among White children, 1 in 2 among Hispanic children but rises to 3 in 4 for Black children; cumulative receipt is also higher in nonmetropolitan counties than in metropolitan counties. We discuss implications of these findings for both research and policy below.

However, while the use of linked administrative data provides important insight into program participation throughout the early childhood period, it is not without its limitations. First, the data analyzed here only report annual household participation. As a consequence, participation spells of as little as 1 month and as much as 12 months (if the 12 months are January to December) cannot be distinguished. This is particularly relevant for our analysis of persistence in Table 2, which may reflect both continuous participation and repeated spells of participation across years. Second, this study relies upon data from only one state. While Virginia is comparable to the US population in racial diversity, economic conditions, and contains a variety of urban, rural, and suburban geographic areas, the state has some characteristics (such as the proximity to Washington, D.C. and policy context) that set it apart. Therefore, our results are only suggestive of conditions in other states. Future research using

Footnote 16 (continued)

exclusively in the county. Similar results emerge, though—-mechanically—we observe slightly lower participation rates when including children who only live in nonmetropolitan counties than we did when we retain those who move (ranging from 60.9 to $64.4 \%$ ). 
administrative data from other contexts will help shed light on the ways participation in Virginia is representative or unique from other states.

Ultimately, our findings regarding the high levels of program participation among nonwhite and rural children in Virginia provide a mixed signal about structural inequality in America. On the one hand, households receive SNAP and TANF because they are poor; the high levels of social welfare participation among certain children, therefore, are the result of the high levels of economic needs that children in such households face during a pivotal point in their childhood. Unfortunately, economic need in this country is structured by race, ethnicity, and geography, so our results reflect those inequities. On the other hand, access to social welfare programs is a positive signal that social welfare regimes have been designed in ways that nonwhite households and those across geographical areas are able access the programs for which they are eligible and receive public support. An important potential exception to this interpretation is the lack of access for Hispanic children in mixed status households, which face legal restrictions because of their household members' immigration status.

\section{Implications for Research}

While it has long been known that the risk of poverty was highest at birth and then declines throughout the life course, most research lacks the ability to incorporate this knowledge directly into the study. We are often forced to take the first observation in a longitudinal file as a good, albeit noisy, indicator of whatever period is left censored. Our study suggests that when we focus on childhood trajectories, we are often only able to observe the tip of the iceberg and that much longer periods of program participation and economic disadvantage precede that which is observed at key points, such as at school entry.

Another implication of our findings shown in Table 4 is that previous estimates of childhood exposure to food stamps using survey data (Rank \& Hirschl, 2009) provided an underestimate of the reach of the SNAP program today. While they estimate that 1 in 4 children received food assistance during early childhood, our estimates are much closer to 1 in 2 on average, with racial breakdowns rising to 3 in 4 among Black children and 2 in 3 among children in nonmetropolitan counties. While some portion of the higher level of program receipt that we observe is the result of changing economic and policy conditions, some is likely due to under-reporting in survey data for participation in means-tested programs. Administrative data are well designed to answer research questions about longitudinal program participation, and we encourage future researchers to utilize such data sources for these questions.

The life course perspective suggests that wellbeing in early childhood has important implications later in life. It is, therefore, important to have a more accurate understanding of how the social safety net functions during early childhood and how it differs by social positioning and spatial location. In fact, given the national conversations around understanding structures that support or 
undermine racism and economic disadvantage, this descriptive analysis is foundational. As demographers, it is our role to provide empirical evidence for how current institutions differentially reach different populations.

\section{Implications for Policy}

Unlike many other developed countries, the United States has no traditionally defined package of family policies to provide a social safety net that specifically targets parents to buffer the extra costs associated with a new birth, such as providing a monthly child allowance or paid family leave (Kamerman \& Kahn, 2001), although expansions in the Child Tax Credit contained in the American Rescue Plan are a step in this direction. As such, American family policy remains ill defined. Scholars debate whether family policy should solely refer to programs that are explicitly designed to target families or be defined more broadly to encompass any policies which affect families (Berger \& Carlson, 2020). We support the comprehensive conceptualization of family policy. Given the reach of SNAP and TANF-with almost 1 in 2 children receiving benefits from these programs at some point before finishing kindergarten-these programs could well be considered the backbone of U.S. family policy. Most children who receive SNAP or TANF in early childhood begin receipt in the birth year, suggesting that these programs are utilized by low-income households to meet essential expenses around the birth of a child. Absent traditional family policy programs, American parents appear to use SNAP, and to some extent TANF, to help cover essential needs. Perhaps as a consequence, reducing childhood poverty remains a substantial policy goal; the National Academies of Sciences, Engineering and Medicine, released a report in 2019 (NAS, 2019), detailing policy options to reduce child poverty by half within 10 years by restructuring the safety net available to families with children.

There is a lengthy literature that already shows that food insecurity during the early childhood period is associated with negative cognitive, behavioral and health outcomes (Alaimo et al., 2002; Bhattacharya et al., 2004; Bronte-Tinkew et al., 2007; Cook \& Frank, 2008; Cook et al., 2013; Duncan et al., 1994; Hernandez \& Jacknowitz, 2009; Howard, 2011; Jyoti et al., 2005; Morgane et al., 1993; Pollitt, 1994; Ryu \& Bartfeld, 2012; Scholl \& Johnson, 2000; Whitaker et al., 2006) and that SNAP participation reduces food insecurity (Ettinger de Cuba et al., 2019; Hoynes \& Ziliak, 2018; Nord \& Golla, 2009; Ratcliffe \& McKernan, 2010). While households with children are not the sole target group of SNAP, our study suggests that the program is a major source of support during a vulnerable part of childhood when social investments have their greatest returns. Going forward, increasing benefits for SNAP are likely to affect a large share of families during their children's early years, disproportionately benefiting black and Hispanic children and those who reside in nonmetropolitan counties.

Finally, this study confirms what many others, notably Edin and Shaefer (2015), have documented: TANF, which may be the only source of cash support for femaleheaded households that are not stably attached to the labor market, is no longer a 
significant source of support for households with young children. In Virginia, the maximum SNAP benefit for a parent with two children is larger than the cash benefit from TANF and is not time limited. Perhaps consequently, TANF caseloads are onequarter the size of SNAP caseloads and most households with young children who receive SNAP do not receive TANF, even in their birth year.

Thus, as the role of TANF in supporting households with young children grows smaller, the role of SNAP grows larger. This presents obstacles for low-income households. While SNAP is a near-cash supplement, it can only be used on food, so SNAP households with young children may have essential needs that remain unmet (such as diapers, hygiene products, bus fare, utilities, rent, etc.) without additional cash inflows. TANF, on the other hand, is a cash transfer, which allows families to use resources on any of their priorities, but TANF is increasingly unused by or unavailable to low-income families with young children.

Nonetheless, given the evidence regarding the ability of SNAP benefits to reduce childhood food insecurity and protect child health, as well as the existing program's reach, SNAP is going to be a critical source of support for many households in America with young children as they weather the public health and economic consequences associated with the COVID-19 pandemic. It is important to document the existing reach of this program, particularly for those living in nonmetropolitan areas and for nonwhite children. The United States has such few federal programs that broadly reach households with young children and provide direct support; we must work to strengthen those we have, particularly during the COVID-19 crisis when so many families with children report being unable to afford basic needs (Center for Budget \& Policy Priorities, 2020). ${ }^{17}$ Finally, it is important that policymakers, educators, and researchers bear in mind that children's reliance on the social safety net observed in the year of school entry may well be just the tip of the iceberg of the receipt children have accumulated since birth and the extent to which this varies by race and ethnicity and space.

Supplementary Information The online version contains supplementary material available at https://doi. org/10.1007/s11113-021-09660-9.

Acknowledgements We are grateful to Jeff Price, Will Goldschmidt, and the staff at the Virginia Department of Social Services for their assistance during this project. We also thank Taryn Morrissey and Laura Tiehen for their valuable comments. This research was funded by the Economic Research Service at the United States Department of Agriculture through cooperative agreement \#58-4000-8-0036R. The opinions expressed are those of the authors and do not represent views of the Virginia Department of Social Services or the U.S. Department of Agriculture.

\section{Declarations}

Conflict of interest The authors declare that they have no conflict of interest.

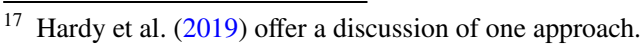




\section{References}

Akee, R. K. Q., Copeland, W. E., Keeler, G., Angold, A., \& Costello, E. J. (2010). Parents' incomes and children's outcomes: A quasi-experiment. American Economic Journal Applied Economics, 2(1), 86-115.

Alaimo, K., Olson, C. M., \& Frongillo, E. A. (2002). Family food insufficiency, but not low family income, is positively associated with dysthymia and suicide symptoms in adolescents. The Journal of Nutrition, 132(4), 719-725.

Bartik, T., \& Randall, E. (1999). Examining the effect of industry trends and structure on welfare caseloads. In S. Danziger (Ed.), Economic conditions and welfare reform (pp. 119-157). Upjohn Institute.

Becker, G. S. (1964). Human capital: A theoretical and empirical analysis, with special reference to education. University of Chicago Press.

Berger, L. M., \& Carlson, M. J. (2020). Family policy and complex contemporary families: A decade in review and implications for the next decade of research and policy practice. Journal of Marriage and Family, 82(1), 478-507.

Bhattacharya, J., Currie, J., \& Haider, S. (2004). Poverty, food insecurity, and nutritional outcomes in children and adults. Journal of Health Economics, 23(4), 839-862.

Bitler, M., \& Hoynes, H. (2016). The more things change, the more they stay the same? The safety net and poverty in the great recession. Journal of Labor Economics, 34(S1), S403-S444.

Blank, R. (2001). What causes public assistance caseloads to grow? Journal of Human Resources, 36(1), 85-118.

Blau, D. M. (1999). The effect of income on child development. Review of Economics and Statistics, 81(2), 261-276.

Bollinger, C. R., \& David, M. H. (1997). Modeling discrete choice with response error: Food stamp participation. Journal of the American Statistical Association, 92(439), 827-835.

Bronfenbrenner, U. (1979). The ecology of human development: Experiments by nature and design. Harvard University Press.

Bronte-Tinkew, J., Zaslow, M., Capps, R., Horowitz, A., \& McNamara, M. (2007). Food insecurity works through depression, parenting, and infant feeding to influence overweight and health in toddlers. The Journal of Nutrition, 137(9), 2160-2165.

Brooks-Gunn, J., \& Duncan, G. J. (1997). The effects of poverty on children. The Future of Children, $7(2), 55-71$.

Carlson, S., Rosenbaum, D., Keith-Jennings, B., \& Nchako, C. (2016). SNAP works for America's children. Center on Budget and Policy Priorities. Retrieved January 11, 2021, from www.cbpp.org.

Celhay, P., Meyer, B. D., \& Mittag, N. (2018). Errors in reporting and imputation of government benefits and their implications. Unpublished manuscript. Retrieved January 11, 2021 from http://home. cerge-ei.cz/mittag/papers/ny_misreporting.pdf.

Center for Budget and Policy Priorities. (2020). A quick guide to SNAP eligibility and benefits tracking the COVID-19 recession's effects on food, housing, and employment hardships. Retrieved January 11, 2021, fromhttps://www.cbpp.org.

Cook, J., \& Frank, D. (2008). Food security, poverty, and human development in the United States. Annals of the New York Academy of Sciences, 1136(1), 193.

Cook, J. T., Black, M., Chilton, M., Cutts, D., Ettinger de Cuba, S., Heeren, T. C., Rose-Jacobs, R., Sandel, M., Casey, P. H., \& Coleman, S. (2013). Are food insecurity's health impacts underestimated in the US population? Marginal food security also predicts adverse health outcomes in young US children and mothers. Advances in Nutrition, 4(1), 51-61.

Corcoran, M. (2001). Mobility, persistence, and the consequences of poverty for children: Child and adult outcomes. In S. Danziger \& R. H. Haveman (Eds.), Understanding poverty (pp. 127-161). Russell Sage Foundation.

Council of Economic Advisers. (1997). Technical report: Explaining the decline in welfare receipt, 1993-1996. Executive Office of the President.

Cronquist, K., \& Lauffer, S. (2019). Characteristics of supplemental nutrition assistance program households: Fiscal year 2017. United States Department of Agriculture. Retrieved January 11, 2021, from https://www.fns.usda.gov/. 
Cunnyngham, K. (2020). Reaching those in need: Estimates of state supplemental nutrition assistance program participation rates in 2017. Prepared by Mathematica Policy Research for the USDA Food and Nutrition Service. Retrieved January 11, 2021, from https://www.fns.usda.gov/.

Dahl, G. B., \& Lochner, L. (2005). The impact of family income on child achievement (No. w11279). National Bureau of Economic Research.

Danielson, C., \& Klerman, J. (2008). Did welfare reform cause the caseload decline? Social Service Review, 82(4), 703-730.

Danielson, C., Thorman, T., \& Bohn, S. (2020). The importance of CalFresh and CalWorks in children's early years. Public Policy Institute of California.

Deb, P., \& Gregory, C. (2016). Who benefits most from SNAP? A study of food security and food spending. NBER Working Paper 22977. Retrieved January 11, 2021, from https://www.nber.org/system/ files/working_papers/w22977/w22977.pdf.

Duncan, G. J., Brooks-Gunn, J., \& Klebanov, P. K. (1994). Economic deprivation and early childhood development. Child Development, 65(2), 296-318.

Duncan, G. J., Morris, P. A., \& Rodrigues, C. (2011). Does money really matter? Estimating impacts of family income on young children's achievement with data from random-assignment experiments. Developmental Psychology, 47(5), 1263-1279.

Duncan, G. J., Yeung, W. J., Brooks-Gunn, J., \& Smith, J. R. (1998). How much does childhood poverty affect the life chances of children? American Sociological Review, 63(3), 406-423. https://doi.org/ $10.2307 / 2657556$

Duncan, G. J., Ziol-Guest, K. M., \& Kalil, A. (2010). Early-childhood poverty and adult attainment, behavior, and health. Child Development, 81(1), 306-325.

Edin, K., \& Shaefer, H. L. (2015). \$2.00 a day: Living on almost nothing in America. Houghton Mifflin Harcourt.

Elder, G. H. (1998). The life course as developmental theory. Child Development, 69(1), 1-12.

Ettinger de Cuba, S., Chilton, M., Bovell-Ammon, A., Knowles, M., Coleman, S. M., Black, M. M., Cutts, D. B., Casey, P. H., Heeren, T. C., \& Frank, D. A. (2019). Loss of SNAP is associated with food insecurity and poor health in working families with young children. Health Affairs, 38(5), $765-773$.

Food Research and Action Center. (2018). Rural Hunger in America: Supplemental Nutrition Assistance Program. Retrieved January 11, 2021, from https://www.frac.org/wp-content/uploads/rural-hungerin-america-snap-get-the-facts.pdf.

Food and Nutrition Service. (2020). SNAP Data Tables. Retrieved January 11, 2021, from https://www. fns.usda.gov/.

Guo, G., \& Harris, K. M. (2000). The mechanisms mediating the effects of poverty on children's intellectual development. Demography, 37(4), 431-447. https://doi.org/10.1353/dem.2000.0005

Hamilton, B. E., Lu, L., Chong, Y., Rossen, L., Lipphardt, A., \& Keralis, J. M. (2020). Natality trends in the United States, 1909-2018. National Center for Health Statistics. Retrieved January 11, 2021, from https://www.cdc.gov/nchs/.

Hardy, B., Hill, H. D., \& Romich, J. (2019). Strengthening Social programs to promote economic stability during childhood. Social Policy Report, 32, 1-36. https://doi.org/10.1002/sop2.4

Harris, K. M. (1996). Life after welfare: Women, work, and repeat dependency. American Sociological Review, 61, 407-426.

Heckman, J. J. (2006). Skill formation and the economics of investing in disadvantaged children. Science, 312(5782), 1900-1902.

Heckman, J. J., Moon, S. H., Pinto, R., Svaelveva, P. A., \& Yavitza, A. (2010). The rate of return to the high/scope perry preschool program. Journal of Public Economics, 94(1-2), 114-128.

Hernandez, D. C., \& Jacknowitz, A. (2009). Transient, but not persistent, adult food insecurity influences toddler development. The Journal of Nutrition, 139(8), 1517-1524.

Howard, L. L. (2011). Does food insecurity at home affect non-cognitive performance at school? A longitudinal analysis of elementary student classroom behavior. Economics of Education Review, 30(1), $157-176$.

Hoynes, H. W., \& Schanzenbach, D. W. (2018). Safety net investments in children (No. w24594). National Bureau of Economic Research.

Hoynes, H. W., \& Ziliak, J. P. (2018). Increasing SNAP purchasing power reduces food insecurity and improves child outcomes. The Brookings Institution. 
Irving, S. K., \& Loveless, T. A. (2015). Dynamics of Economic Well-Being: Participation in Government Programs, 2009-2012: Who Gets Assistance? U.S. Census. Retrieved January 11, 2021, from https://www.census.gov/.

Jyoti, D. F., Frongillo, E. A., \& Jones, S. J. (2005). Food insecurity affects school children's academic performance, weight gain, and social skills. The Journal of Nutrition, 135(12), 2831-2839.

Kamerman, S. B., \& Kahn, A. J. (2001). Child and family policies in the United States at the opening of the twenty-first century. Social Policy \& Administration, 35(1), 69-84.

Kindergarten Instructional Time. (2020). Hearing on Senate Bill 238: Hearing before the Committee on Education and Health, VirginiaState Legislature (testimony of State Senator George Barker)

Mayer, S. E. (1997). What money can't buy: Family income and children's life chances. Harvard University Press.

McKernan, S. M., \& Ratcliffe, C. E. (2002). Transition Events in the Dynamics of Poverty. The Urban Institute.

McLoyd, V. C. (1998). Socioeconomic disadvantage and child development. American Psychologist, 53(2), 185-204. https://doi.org/10.1037/0003-066X.53.2.185

Meyer, B. D., \& Mittag, N. (2019). Using linked survey and administrative data to better measure income: Implications for poverty, program effectiveness and holes in the safety net. American Economic Journal: Applied Economics, 11(2), 176-204.

Meyer, B. D., Mok, W. K. C., \& Sullivan, J. X. (2015). Household surveys in crisis. Journal of Economic Perspectives, 29(4), 199-226.

Meyer, B. D., Mittag, N., \& Goerge, R. (2018). Errors in survey reporting and imputation and their effects on estimates of food stamp program participation. NBER Working Paper 25143. Retrieved January 11, 2021 from https://www.nber.org/system/files/working_papers/w25143/w25143.pdf.

Moffitt, R. A. (2013). The great recession and the social safety net. The Annals of the American Academy of Political and Social Science, 650(1), 143-166.

Morgane, P. J., Austin-LaFrance, R., Bronzino, J., Tonkiss, J., Diaz-Cintra, S., Cintra, L., Kemper, T., \& Galler, J. R. (1993). Prenatal malnutrition and development of the brain. Neuroscience \& Biobehavioral Reviews, 17(1), 91-128.

National Academies of Sciences, Engineering, and Medicine. (2019). A Roadmap to reducing child poverty. The National Academies Press. https://doi.org/10.17226/25246

National Center for Children in Poverty. (2018). Virginia demographics of young, low-income children. Retrieved April 1, 2020 from http://www.nccp.org/profiles/VA_profile_8.html

Newman, C., Todd, J. E., \& Ver Ploeg, M. (2011). Children's participation in multiple food assistance programs: Changes from 1990 to 2009. Social Service Review, 85(4), 535-564.

Nord, M., \& Golla, M. (2009). Does SNAP decrease food insecurity: Untangling the self-selection effect (Economic Research Service Report No. 85). US Department of Agriculture.

Pollitt, E. (1994). Poverty and child development: Relevance of research in developing 1 countries to the United States. Child Development, 65(2), 283-295.

Rank, M. R., \& Hirschl, T. A. (2009). Estimating the risk of food stamp use and impoverishment during childhood. Archives of Pediatrics \& Adolescent Medicine, 163(11), 994-999.

Ratcliffe, C., \& McKernan, S. M. (2010). Childhood poverty persistence: Facts and consequences. The Urban Institute.

Reardon, S. F. (2011). The widening academic achievement gap between the rich and the poor: New evidence and possible explanations. In G. J. Duncan \& R. J. Murnane (Eds.), Whither opportunity? Rising inequality, schools, and children's life chances (pp. 91-115). Russell Sage Foundation \& Spencer Foundation.

Reardon, S. F., \& Portilla, X. A. (2016). Recent trends in income, racial, and ethnic school readiness gaps at kindergarten entry. AERA Open, 2(3), 233285841665734.

Ryu, J. H., \& Bartfeld, J. S. (2012). Household food insecurity during childhood and subsequent health status: The early childhood longitudinal study-kindergarten cohort. American Journal of Public Health, 102(11), e50-e55.

Safawi, A., \& Floyd, I. (2020). TANF benefits still too low to help families, especially black families, avoid increased hardship. Center on Budget and Policy Priorities.

Schanzenbach, D. W., \& Thorn, B. (2019). Food support programs and their impacts on very young children. Health Affairs, Health Policy Brief. https://doi.org/10.1377/hpb20190301.863688

Scholl, T. O., \& Johnson, W. G. (2000). Folic acid: Influence on the outcome of pregnancy. The American Journal of Clinical Nutrition, 71(5), 1295S-1303S. 
Semega, J., Kollar, M., Shrider, E. A., \& Creamer, J. F. (2020). Income and poverty in the United States: 2019. Current Population Reports, U.S. Census Bureau.

Shaefer, H. L., \& Edin, K. (2013). Rising extreme poverty in the United States and the response of federal means-tested transfer programs. Social Service Review, 87(2), 250-268.

Smith, J. R., Brooks-Gunn, J., \& Klebanov, P. K. (1997). Consequences of living in poverty for young children's cognitive and verbal ability and early school achievement. In G. J. Duncan \& J. BrooksGunn (Eds.), Consequences of growing up poor (pp. 132-189). Russell Sage Foundation.

Stoll, M. A. (2013). Residential Mobility in the U.S. and the Great Recession: A Shift to Local Moves. US2010 Project. Retrieved January 11, 2021 from https://s4.ad.brown.edu/Projects/.

Tiehen, L., Jolliffe, D., \& Gunderson, C. (2012). Alleviating poverty in the United States: The critical role of SNAP benefits. U.S. Department of Agriculture. Retrieved January 11, 2021 from https://www. ers.usda.gov/webdocs/publications/44963/17742_err132_1_.pdf?v=4372.

United States Health and Human Services: Office of Family Assistance. (2004). Caseload Data 1995 AFDC Total Caseload. Retrieved January 11, 2021 from https://www.acf.hhs.gov/.

United States Health and Human Services: Office of Family Assistance. (2019). Characteristics and Financial Circumstances of TANF Recipients, Fiscal Year 2018. Retrieved January 11, 2021 from https://www.acf.hhs.gov/.

United States Department of Agriculture. (2020). Supplemental Nutrition Assistance Program Participation and Costs. Retrieved January 11, 2021 from https://www.fns.usda.gov/.

Vigil, A. (2019). Trends in Supplemental Nutrition Assistance Program Participation Rates: Fiscal Year 2010 to Fiscal Year 2017. Prepared by Mathematica Policy Research for the USDA Food and Nutrition Service. Retrieved January 11, 2021 from https://www.fns.usda.gov/.

Virginia Department of Social Services Office of Research \& Planning. (2012). How long do families stay on TANF? Retrieved January 11, 2021 from https://www.dss.virginia.gov.

Virginia Department of Social Services. (2019). Virginia supplement nutrition assistance program manual. Retrieved January 11, 2021 from https://snapmanual.dss.virginia.gov/.

Virginia Department of Social Services. (2020). Temporary Assistance for Needy Families (TANF) Reports. Retrieved January 11, 2021 from https://dss.virginia.gov/geninfo/reports/financial_assis tance/tanf.cgi.

Whitaker, R. C., Phillips, S. M., \& Orzol, S. M. (2006). Food insecurity and the risks of depression and anxiety in mothers and behavior problems in their preschool-aged children. Pediatrics, 118(3), e859-e868.

Ziliak, J. P. (2016). Temporary assistance for needy families. In R. A. Moffitt (Ed.), Economics of meanstested transfer programs in the United States (Vol. 1, pp. 303-393). National Bureau of Economic Research and University of Chicago Press.

Ziliak, J. P., Figlio, D., Davis, E., \& Connolly, L. (2000). Accounting for the decline in AFDC caseloads: Welfare reform or the economy? Journal of Human Resources, 35(3), 570-586.

Publisher's Note Springer Nature remains neutral with regard to jurisdictional claims in published maps and institutional affiliations. 